\title{
A Conserved Carboxylesterase Inhibits Tobacco mosaic virus (TMV) Accumulation in Nicotiana benthamiana Plants
}

\author{
Song Guo ${ }^{1,2}$ and Sek-Man Wong ${ }^{1,2,3, *}$ \\ 1 Department of Biological Sciences, National University of Singapore, Singapore 117543, Singapore; \\ dbsguos@nus.edu.sg \\ 2 National University of Singapore (Suzhou) Research Institute, Suzhou 215123, China \\ 3 Temasek Life Sciences Laboratory, 1 Research Link, Singapore 117604, Singapore \\ * Correspondence: dbswsm@nus.edu.sg; Tel.: +65-65162976; Fax: +65-67792486
}

Received: 2 December 2019; Accepted: 7 February 2020; Published: 10 February 2020

\begin{abstract}
A carboxylesterase (CXE) or carboxylic-ester hydrolase is an enzyme that catalyzes carboxylic ester and water into alcohol and carboxylate. In plants, CXEs have been implicated in defense, development, and secondary metabolism. We discovered a new CXE gene in Nicotiana benthamiana that is related to virus resistance. The transcriptional level of $\mathrm{NbCXE}$ expression was significantly increased after Tobacco mosaic virus (TMV) infection. Transient over-expression of NbCXE inhibited TMV accumulation in N. benthamiana plants. Conversely, when the NbCXE gene was silenced with a Tobacco rattle virus (TRV)-based gene silencing system, TMV RNA accumulation was increased in $\mathrm{NbCXE}$-silenced plants after infection. NbCXE protein was shown to interact with TMV coat protein (CP) in vitro. Additionally, the expressions of host defense-related genes were increased in transient NbCXE-overexpressed plants but decreased in NbCXE silenced N. benthamiana plants. In summary, our study showed that $\mathrm{NbCXE}$ is a novel resistance-related gene involved in host defense responses against TMV infection.
\end{abstract}

Keywords: Carboxylesterase; Tobacco mosaic virus; host resistance; coat protein

\section{Introduction}

Carboxylesterases (CXEs) are found in all kingdoms of life. They are enzymes that catalyze the hydrolysis of carboxylic esters into their corresponding alcohols and carboxylic acids [1]. In animals and microbes, many CXEs have been cloned and characterized [2-4]. They are involved in a broad range of functions, including processing and degradation of neurotransmitters, hormones, and xenobiotics $[5,6]$.

Carboxylesterases (CXEs) are also widely distributed in plants. They are expressed in many tissues, including fruits, leaves, and roots [7-9]. Plant CXEs have been implicated in defense, development, and secondary metabolism [10-13]. Some plant CXEs have developed new activities. For example, at least two CXEs in legumes have attained additional dehydratase activity and are involved in isoflavone biosynthesis [14]. In rice, a putative CXE has lost carboxylesterase activity and functions as a receptor for gibberellic acid [15].

Plant CXEs are classified into three classes based on sequence features. Classes I and II belong to the $\alpha / \beta$ hydrolase fold superfamily. Enzymes in class I share several sequence features, typically the His-Gly-Gly (HGG) motif and the Ser-His-Asp catalytic triad [16]. The first plant carboxylesterase to be identified was the Hsr203J protein of $N$. tabacum, which is induced during hypersensitive reactions (HRs) and possesses ester-hydrolyzing activity [17]. Enzymes in class II were originally identified as being related to flavin adenine dinucleotide (FAD)-independent hydroxynitrile lyases (HNLs) 
of cassava (Manihot esculenta) and the tropical rubber tree (Hevea brasiliensis) $[18,19]$. They have been shown to preferentially catalyze methyl ester hydrolysis. Class III enzymes are completely unrelated to $\alpha / \beta$ hydrolases and belong to the Gly-Asp-Ser (GDS) hydrolase family [16].

In most cases, a sequence annotated as "carboxylesterases" in the database means it belongs to the class I enzymes. For example, a family of 20 plant carboxylesterases have been identified from the Arobidopsis thaliana genome and designated as AtCXE1-AtCXE20. These AtCXEs genes are widely distributed across the genome, present in four out of five chromosomes. Multiple-sequence alignment results show conserved motifs among all AtCXEs [20].

Carboxylesterases are also a class of the metabolic enzymes that have been shown to be involved in the resistance of insects to organophosphate insecticides and pyrethroids through gene amplification, upregulation, and coding sequencing mutations [21]. CXEs also play important roles in herbicide activation. These plant CXEs detoxify persistent pollutants and insecticides, as well as hydrolyzing pro-herbicide esters to their bioactive free acids. As many major herbicides are applied as esters to facilitate penetration into the leaf, ester hydrolysis by plant CXEs is required to activate those herbicides [22].

Plants have evolved several mechanisms to protect themselves against pathogen attacks. Hypersensitive response is one of the most common and efficient plant reactions to pathogens [23]. The HR is characterized by rapid cell death in the local region surrounding an infection. The HR restricts the growth and spread of pathogens to other plant parts [24]. Hypersensitive cell death occurs via the recognition of pathogen avirulence (avr) genes by plant resistance (R) genes [25]. Besides direct $R$ genes, there are also several hypersensitive-related genes that can trigger plant cell death. For example, Hsr203J is a tobacco gene associated with an HR to the bacterium Ralstonia solanacearum [26]. Also, the Lehsr203 gene is another HR-related gene in tomato [27]. SOBER1 in Arabidopsis functions as a negative regulator of the HR, triggered by the bacterial type III effector protein AvrBsT. Furthermore, SOBER1 is not restricted to $A$. thaliana and only limited to suppress AvrBsT-induced HR [28].

Chenopodium quinoa and C. amaranticolor are local lesion hosts of many plant viruses. Using Tobacco mosaic virus (TMV)-tagged with green fluorescent protein (GFP) to infect $C$. quinoa and C. amaranticolor, a group of short fragment sequences were highly expressed in these two plants at 4 days post-TMV-GFP infection. Those short sequences in $C$. amaranticolor are termed as disease-expressed sequences in C. ameranticolor (DESCA) genes, which are closely associated with pathogen defense in plants. Expression of these DESCA genes are also induced by Tobacco rattle virus (TRV) infection. In C. quinoa, DESCA5 was increased 1,100 fold at 4 dpi after TMV infection [29]. The BLAST results showed that DESCA5 is similar to a yeast potential transcriptional regulator. The reason whyDESCA5 highly increased after TMV infection in C. quinoa is unknown.

In this study, we aligned the DESCA5 sequence to the whole genome of $C$. quinoa and found that it matched a carboxylesterase (CXE) gene. A similar gene in N. benthamiana was amplified and named $\mathrm{NbCXE}$. Similar to that of DESCA5 in C. quinoa, the transcriptional level of NbCXE was also highly expressed in N. benthamiana at 4 dpi after TMV infection. Transient over-expression of NbCXE could inhibit TMV RNA accumulation. Conversely, silencing of NbCXE increased accumulation of TMV RNA and coat protein $(\mathrm{CP})$ in infected leaves. Moreover, NbCXE could interact with TMV CP in a yeast two-hybrid system. Our study revealed that $\mathrm{NbCXE}$ is a newly discovered resistance-related gene in N. benthamiana and its expression inhibits TMV accumulation.

\section{Materials and Methods}

\subsection{Plant Materials and Virus Inoculation}

$N$. benthamiana plants were grown at $24{ }^{\circ} \mathrm{C}$ in a growth room under a $16 \mathrm{~h} \mathrm{light} / 8 \mathrm{~h}$ dark cycle. Fully expanded leaves of 4-week-old plants were mechanically inoculated with $2 \mu \mathrm{g}$ in vitro transcribed viral RNA in a GKP buffer ( $50 \mathrm{mM}$ glycine; $30 \mathrm{mM} \mathrm{K}_{2} \mathrm{HPO}_{4}, \mathrm{pH} 9.2 ; 1 \%$ bentonite; $1 \%$ celite). 


\subsection{Construction of NbCXE Over-Expression and TRV Silencing Vectors}

The complete open reading frame (ORF) of the $\mathrm{NbCXE}$ gene was inserted into a pGreen vector with a GFP tag using primers F-NbCXE-EcoRI and R-NbCXE-BamHI, termed 35S-NbCXE-GFP. The TRV binary vectors pTRV1 and TRV RNA2 were used for the silencing study. DNA fragments used for the silencing study were amplified from $N$. benthamiana cDNA by RT-PCR with primers F-NbCXE-EcoRI and $\mathrm{R}-\mathrm{NbCXE} \mathrm{E}_{400}-\mathrm{Bam} \mathrm{HI}$. The nucleotide sequences of all the primers used are listed in Supplementary Table S1.

\subsection{Transient Over-Expression of NbCXE and TRV-Based Gene Silencing of NbCXE}

The vector 35S-NbCXE-GFP and TRV2:NbCXE silencing vectors were introduced into the Agrobacterium strain GV3101 by electroporation (BIO-RAD, Hercules, CA, USA) separately. $N$. benthamiana plants at the 6 to 10 leaf-stage were used for agroinfiltration. The appropriate binary plasmids in Agrobacterium were grown overnight at $28{ }^{\circ} \mathrm{C}$ and cultures were diluted to cell density of 0.6 at $\mathrm{OD}$ and $600 \mathrm{~nm}$, and were infiltrated into the abaxial leaves of $N$. benthamiana immediately above the cotyledons using a $1 \mathrm{~mL}$ syringe.

For agroinfiltration-based transient over-expression of $\mathrm{NbCXE}$, in vitro transcribed TMV RNA $(2 \mu \mathrm{g})$ was inoculated in the infiltrated leave of plants at 3 days post-infiltration. The inoculated leaves were collected at 7 days post-inoculation for RNA isolation, Western blot analysis, and qRT-PCR experiments. For the TRV-induced $\mathrm{NbCXE}$ gene silencing system, in vitro transcribed TMV RNA $(2 \mu \mathrm{g})$ was inoculated in the infiltrated leaves at 7 days post-infiltration. The inoculated leaves were collected at 7 days post-inoculation for further experiments.

\subsection{Total RNA Isolation and Western Blot}

For the $\mathrm{NbCXE}$ transient over-expression experiment, plant total RNAs were extracted from infiltrated leaves at 3 days post-infiltration to detect $\mathrm{NbCXE}$ transcriptional expression levels. For $\mathrm{NbCXE}$ silencing plants, the expression level of $\mathrm{NbCXE}$ was detected from infiltrated leaves and upper leaves at 7 days post-infiltration. Total RNA was isolated using TRIzol reagents, following the manufacturer's instructions.

For both $\mathrm{NbCXE}$ transient over-expression and $\mathrm{NbCXE}$-silenced experiments, three biological repeats were carried out in each treatment of the experiment. Each experiment was repeated two times. Total RNAs and total proteins were extracted from infected plants at 7 days post-inoculation. Total proteins were separated on 15\% SDS-PAGE gel, then transferred to nitrocellulose membrane (Bio-Rad). The Western blot was carried out to detect TMV CP expression with anti-TMV CP antibody. The CP band was visualized using 5-bromo-4-chloro-3-indolyl phosphate and nitroblue tetrazolium (NBT/BCIP) from Sigma-Aldrich Chemical Company (St Louis, MO, USA). The band intensity was quantified using the ImageJ software (https://imagej.nih.gov/ij/).

\section{5. $q R T-P C R$ Analysis}

The complete ORF of NbCXE was amplified from total RNA of healthy N. benthamiana plants through RT-PCR using the Superscript III ${ }^{\mathrm{TM}}$ First-Strand Synthesis System (Invitrogen, Carlsbad, CA, USA) and KOD-plus-Neo DNA polymerase (Toyobo, Tokyo, Japan) with primers NbCXE-F and NbCXE-R. qRT-PCR was performed in triplicate with KAPA SYBR on the CFX384 Real-Time PCR system (Bio-Rad) with primers $\mathrm{NbCXE-qF}$ and $\mathrm{NbCXE-qR}$. The actin gene was used as an internal control with primers actin-qF and actin-qR. The experiment was repeated twice. To quantify TMV RNA accumulation in inoculated plants, total RNA from each of the triplicate samples of each treatment was extracted and reverse transcribed by using Superscript III Reverse Transcriptase (Life Technologies, Invitrogen) with primer TMV-R. qRT-PCR was performed in triplicate with primers TMV-qF and TMV-qR, using the actin gene as an internal control. 
To quantify fold changes of selected host response genes (NPR1, HIN1, HSP203J, PR1, and PR3) in transient $\mathrm{NbCXE}$ over-expressed and $\mathrm{NbCXE}$-silenced $\mathrm{N}$. benthamiana, total RNA from each of the triplicate samples of each treatment was extracted and reverse transcribed using Superscript III Reverse Transcriptase (Life Technologies, Invitrogen) with a specific reverse primer. qRT-PCR was performed in triplicate with specific forward and reverse primers (Supplementary Table S1). The actin gene was used as an internal control. Each experiment was repeated twice.

For qRT-PCR analysis, the $5 \mu \mathrm{L}$ reaction mixture contained $20 \mathrm{ng}$ of cDNA, $200 \mathrm{nM}$ of each pair of target primers, and $2.5 \mu \mathrm{L}$ of $2 \times$ SYBR Green PCR Master Mix. PCR conditions were as follows: $95^{\circ} \mathrm{C}$ for $3 \mathrm{~min}$, followed by 40 cycles of $95^{\circ} \mathrm{C}$ for $10 \mathrm{~s}$ and $60^{\circ} \mathrm{C}$ for $30 \mathrm{~s}$. Three technical replicates from three independent biological replicates were performed for qRT-PCR. The data were analyzed according to the $2^{-\Delta \Delta C T}$ method. The actin gene was used as a reference gene for analysis. Each experiment was repeated twice.

\subsection{Yeast Two-Hybrid Assay}

The full-length TMV CP gene was PCR amplified and cloned into a yeast pGADT7 vector (BD Biosciences Clontech, Palo Alto, CA, USA) to generate AD-TMV CP using primers F-TMV CP-EcoRI and R-TMVCP-BamHI. The full-length NbCXE gene was PCR amplified and cloned into the pGBKT7 vector (BD Biosciences Clontech) to generate BD-NbCXE with primers F-NbCXE-EcoRI and R-NbCXE-BamHI. The yeast strain AH109 (BD Biosciences Clontech) was co-transformed with $500 \mathrm{ng}$ of individual plasmids using the polyethylene glycol-lithium acetate (PEG/LiAC) method. The transformants were cultured on a synthetic drop-out (SD) medium containing all amino acids except leucine and tryptophan (SD-Leu-Trp) at $30^{\circ} \mathrm{C}$ for 3-4 days. Empty vector AD with BD-NbCXE and empty vector $\mathrm{BD}$ with $\mathrm{AD}-\mathrm{TMVCP}$ were performed as controls.

A single colony was selected from each of the transformants and grown in $2 \mathrm{~mL}$ of SD-Leu-Trp medium at $30^{\circ} \mathrm{C}$ for $24 \mathrm{~h}$. The culture densities were normalized with SD-Leu-Trp, followed by three 10-fold serial dilutions. Ten $\mu \mathrm{L}$ each of the 1:1000 diluted cultures were grown on SD-Leu-Trp and SD-Leu-Trp-His-Ade growth medium at $30^{\circ} \mathrm{C}$ for 3-4 days. Amino acids Leu, Trp, His, Ade denote leucine, tryptophan, histidine, and adenine, respectively. The experiment was repeated twice.

\section{Results}

\subsection{Identification of the New Resistance-Related Gene NbCXE in N. benthamiana Plants}

The DESCA 5 sequence was registered in the NCBI database as "DESCA 5 cDNA-AFLP Chenopodium amaranticolor cDNA EcoRI, mRNA sequence" with a GenBank accession number of BI534451.1. After aligning the DESCA5 sequence against the whole genome of C. quinoa, it showed a $96.40 \%$ identity with the sequence of "Predicted: C. quinoa probable carboxylesterase (LOC110718167), mRNA". As $N$. benthamiana is a model plant for virus study and a systemic host of TMV, we decided to investigate the CXE gene in relation to TMV infection in N. benthamiana plants.

Based on the N. sylvestris carboxylesterase (XP_009605841) sequence for primer design, the carboxylesterase gene of $N$. benthamiana (NbCXE) was amplified successfully. In order to ascertain whether this $\mathrm{NbCXE}$ is a plant resistance-related protein, amino acid sequences of the amplified $\mathrm{NbCXE}$ were compared with three known Hsr203J protein sequences in N. tabacum (AAF62404.1, BAC15624.1 and CAA54393.1). The amino acid sequences of NbCXE showed a low identity with the Hsr203J protein of $N$. tabacum, which indicated that it is not related to the Hsr203J resistance protein (Figure 1A). However, the expression of $\mathrm{NbCXE}$ showed a significant increase in expression at $4 \mathrm{dpi}$ in TMV-infected plants (Figure 1B), similar to that of DESCA5 in C. quinoa, which suggested that it is related to resistance against TMV infection. 
(A)

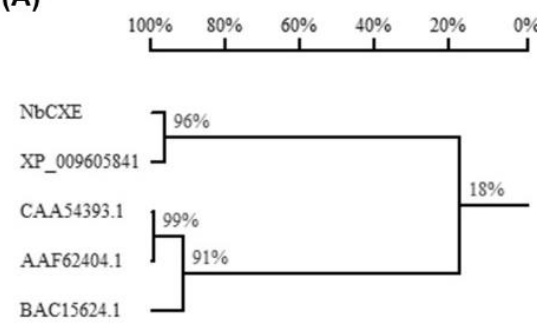

(B)

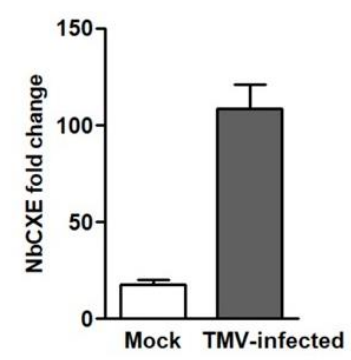

Figure 1. (A) Alignment of amino acid sequence of $\mathrm{NbCXE}$ with carboxylesterase in Nicotiana sylvestris and the Hsr203J proteins in Nicotiana tabacum. (XP_009605841 are the carboxylesterases in Nicotiana sylvestris; CAA54393.1, BAC15624.1 and AAF62404 are Hsr203J proteins in Nicotiana tabacum). (B) Expression of $\mathrm{NbCXE}$ showed a significant increase at $4 \mathrm{dpi}$ in TMV-infected N. benthamiana plants.

\subsection{Over-Expression of NbCXE Inhibited TMV Accumulation in N. benthamiana Plants}

Since $\mathrm{NbCXE}$ was upregulated after TMV infection, over-expression of NbCXE should inhibit TMV accumulation. To test this hypothesis, $\mathrm{NbCXE}$ was transiently over-expressed through agroinfiltration. The transcriptional level of $\mathrm{NbCXE}$ was increased at 3 days post-infiltration (Figure 2A). At 7 dpi, TMV RNA accumulation in the inoculated leaves of 35S NbCXE-infiltrated plants was significantly lower than that of the inoculated leaves of $35 \mathrm{~S}$ vector-infiltrated control plants (Figure $2 \mathrm{~B}$ ). The $\mathrm{NbCXE}$ transiently over-expressed leaves accumulated a lower amount of TMV CP (Figure 2C). These results confirmed that the over-expression of $\mathrm{NbCXE}$ resulted in lower TMV accumulation in the infected plants.

(A)

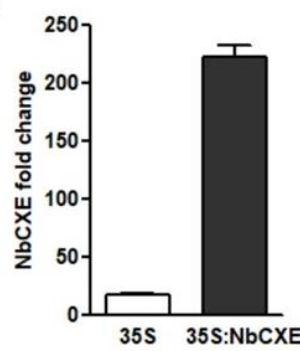

(B)

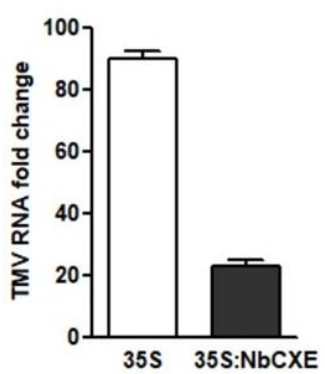

(C)

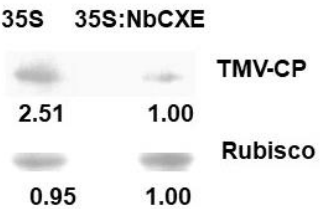

Figure 2. (A) After transient over-expression of NbCXE in N. benthamiana plants, the transcriptional level of $\mathrm{NbCXE}$ was increased at 3 days post-infiltration. (B) TMV RNA accumulation in the NbCXE-overexpressed leaves was significantly lower than that in the control plants. (C) NbCXE transient overexpressed leaves accumulated a lower level of TMV CP, as compared with that of the control plants.

\subsection{Silencing of NbCXE Enhanced TMV Accumulation}

$\mathrm{NbCXE}$ was silenced through the TRV gene silencing system. After agroinfiltration, the transcriptional level of $\mathrm{NbCXE}$ was downregulated about 40 fold in the infiltrated leaves of plants (Figure 3A). Subsequently, TMV was inoculated to the infiltrated leaves and the accumulation of TMV RNA and CP after 7 dpi was monitored. The results showed that more TMV RNA (Figure 3B) and CP (Figure 3C) were accumulated in the $\mathrm{NbCXE}$ silencing plants than the control plants. Silencing of $\mathrm{NbCXE}$ enhanced higher TMV accumulation in plants. 
(A)

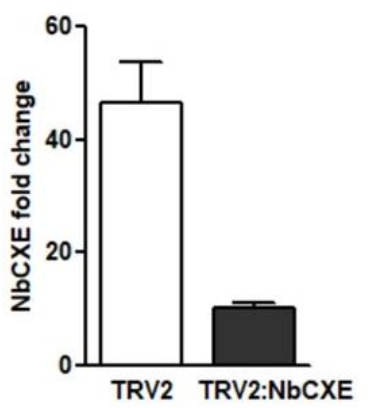

(C) TRV2 TRV2:NbCXE

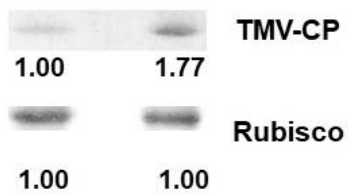

(B)

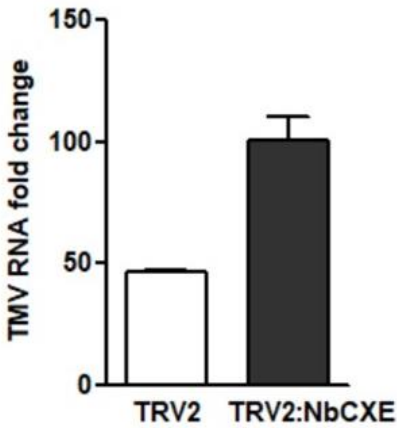

Figure 3. (A) The transcriptional level of $\mathrm{NbCXE}$ was down-regulated about 40 fold in the $\mathrm{NbCXE}$-silencing plants, as compared to that of control plants. (B) Higher TMV RNA accumulation was detected in the NbCXE silencing plants than in the control plants. (C) Higher TMV CP was detected in the NbCXE silencing plants, as compared with that of control plants.

\subsection{Interaction of $\mathrm{NbCXE}$ with TMV CP}

TMV CP plays an important role in TMV replication. Since expression of NbCXE in plants affects TMV accumulation, there might be an interaction between NbCXE and TMV CP. A yeast two-hybrid experiment was performed and showed an interaction between NbCXE and TMV CP (Figure 4).

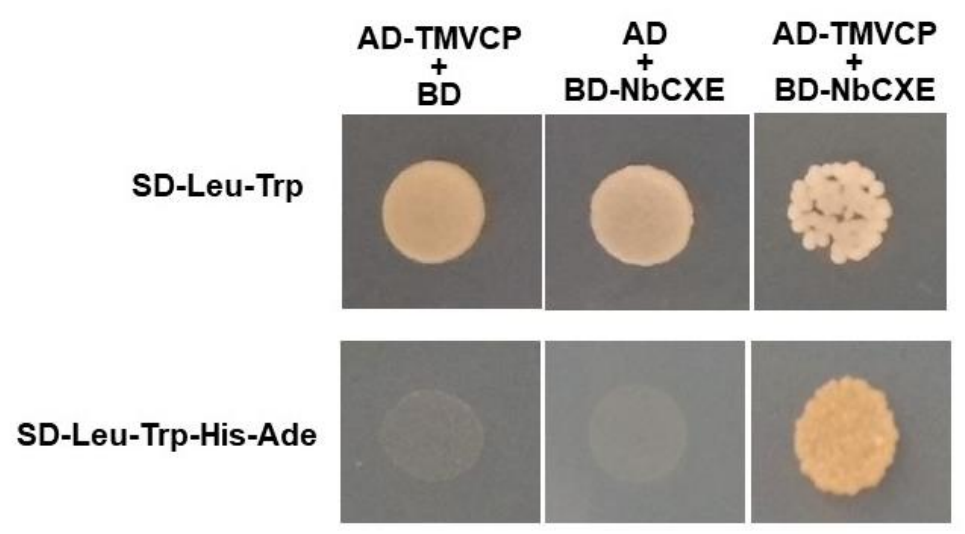

Figure 4. Yeast two-hybrid results showed an interaction between NbCXE and TMV CP.

3.5. Expression of Host Defense-Related Genes Increased in Transient NbCXE-Overexpressed Plants but Decreased in NbCXE-Silenced N. benthamiana Plants

To analyze the effects of $\mathrm{NbCXE}$ in host defense signaling, we examined the expression of several host defense-related genes in transient $\mathrm{NbCXE}$-overexpressed plants and $\mathrm{NbCXE}$-silenced plants after TMV infection, respectively. These genes included the important defense regulatory gene NPR1, HR marker genes HIN1 and Hsr203J, and the two pathogenesis-related (PR) genes PR1 and PR3. These host defense-related genes showed a higher expression in transient $\mathrm{NbCXE-overexpressed}$ plants but decreased in NbCXE-silenced plants (Figure 5A,B). This indicated that NbCXE is involved 
in host defense responses. Overexpression or silencing of NbCXE affects the expression levels of defense-related genes in host plants.

(A)

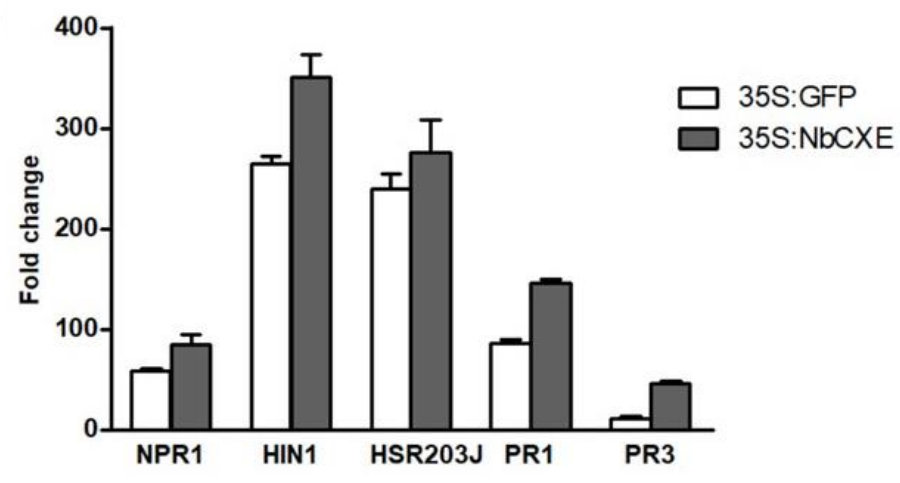

(B)

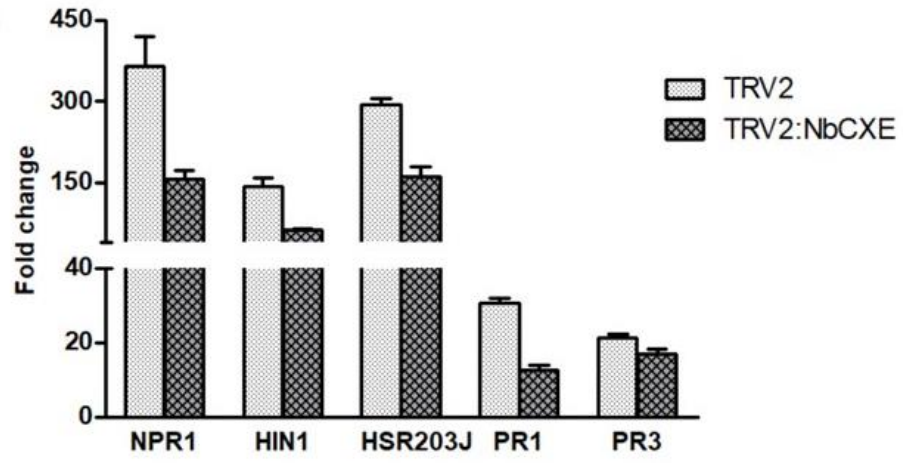

Figure 5. After TMV infection, the fold changes of selected host response genes (NPR1, HIN1, HSP203J, PR1 and PR3) in (A) transient NbCXE-overexpressed and (B) NbCXE-silenced N. benthamiana, respectively.

\section{Discussion}

\subsection{NbCXE Encoded a Resistance-Related Protein}

Resistance $(\mathrm{R})$ genes in plant genomes convey plant disease resistance against pathogens by producing $R$ proteins. The main class of $R$ genes consists of a nucleotide binding domain (NB) and leucine-rich repeat (LRR) domains. The NB domain binds either ATP/ADP or GTP/GDP. The LRR domain is involved in protein-protein interactions as well as ligand binding [30,31]. Some $R$ proteins can interact directly with a virulent protein produced by a pathogen [32-34]. They may detect a pathogen-associated molecular pattern or encodes enzymes that degrade toxins produced by pathogens [35]. Once the R protein has detected a pathogen, it will stimulate the host defense system against the pathogen [36]. TMV virulent protein is located in its helicase domain of the 126-kD replicase [37,38]. As NbCXE was increased after TMV infection and the expression of NbCXE in plants significantly inhibited TMV RNA accumulation after infection, it can be suggested that $\mathrm{NbCXE}$ is a plant resistance-related protein.

Carboxylesterase is an important class of detoxification enzymes involved in insecticide resistance. The relative transcriptional levels of carboxylesterases are much higher in resistant strains than in susceptible strains. Over-expression of carboxylesterase contributes to increased insecticide omethoate resistance in cotton aphids [39]. Oral delivery-mediated RNA silencing of the carboxylesterase gene in cotton aphids reduced its resistance to insecticides. This shows that insect CXE gene plays a major role in insecticide resistance [40]. Our results showed that the NbCXE gene is important for resistance against TMV infection in N. benthamiana plants. Over-expression of NbCXE showed an enhanced defense response to TMV infection, while silencing of NbCXE compromised host resistance to TMV infection and resulted in an increased viral RNA accumulation in infected plants. 
Transgenic pepper plants overexpressing a pepper carboxylesterase gene exhibit a higher resistance against multiple fungal pathogens [41]. Moreover, applying the pepper carboxylesterase protein on the surface of unripe pepper fruits leads to disease resistance in the fruits, including generation of hydrogen peroxide and expression of pathogenesis-related (PR) proteins with antimicrobial activity [41]. In our study, the transiently over-expressed $\mathrm{NbCXE}$ enhanced plant resistance against TMV infection. The important defense regulatory gene NPR1 and HR marker genes HIN1 and Hsr203J, PR1, and PR3 were all upregulated in transient $\mathrm{NbCXE}$-overexpressed plants, implying an enhanced host defense response to TMV infection. Conversely, these host defense-related genes were reduced in expression in $\mathrm{NbCXE}$-silenced plants, indicating that the host defense resulted in a higher TMV RNA accumulation in host plants. All these results indicated that NbCXE is a resistance-related gene associated with host defense response.

\subsection{NbCXE Interacted with TMV CP}

Plant resistance (R) genes confer resistance to various viruses. In some cases, viral CPs can be specifically recognized by the host $\mathrm{R}$ genes. For example, the Rx1 resistance gene of Solanum tumberosum can recognize the $\mathrm{CP}$ of Potato virus $\mathrm{X}$ (PVX) and induce a hypersensitive response that leads to resistance against PVX [42]. Moreover, it has been reported that the R genes in Arabidopsis and tomato conferred CP-mediated resistance to Turnip crinkle virus [43] and Cucumber mosaic virus [44], respectively. That the expression of TMV CP in plants confers resistance to infection by TMV and related tobamoviruses is because transgenic TMV CP in plants interferes with virus disassembly after virus entry [45]. Our study showed that there is interaction between host NbCXE and TMV CP. This provides a new perspective to the mechanism of $\mathrm{CP}$-mediated resistance. The host carboxylesterase recognizes TMV CP through its direct interaction and link to the host defense signaling pathway to provide an enhanced resistance to virus infection. TMV CP plays an important role in TMV replication as it forms part of a viral replication complex [46]. The interaction between NbCXE and TMV CP has been shown in this study.

In conclusion, our study showed that $\mathrm{NbCXE}$ is a new plant resistance-related gene involved in host defense responses against TMV infection in N. benthamiana plants.

Supplementary Materials: The following are available online at http://www.mdpi.com/1999-4915/12/2/195/s1, Table S1: The nucleotide sequences of all the primers used in this study.

Author Contributions: Conceptualization, S.G. and S.-M.W.; Formal Analysis, S.G.; Investigation, S.G. and S.-M.W.; Resources, S.G. and S.-M.W.; Validation, S.G; Data curation, S.G.; Writing—original draft, S.G.; Writing—review and editing, S.G. and S.-M.W. All authors have read and agreed to the published version of the manuscript.

Funding: This research was funded by Singapore Ministry of Education Tier 1 Academic Research grant R-154-000-B23-114 through National University of Singapore. Suzhou Science \& Technology Bureau grant SNG2018039 and National Natural Science Foundation of China grant 31872639.

Conflicts of Interest: The authors declare no conflict of interest. The funders had no role in the design of the study; in the collection, analyses, or interpretation of data; in the writing of the manuscript; or in the decision to publish the results.

\section{References}

1. Chen, Y.; Black, D.S.; Reilly, P.J. Carboxylic ester hydrolases: Classification and database derived from their primary, secondary, and tertiary structures. Protein Sci. 2016, 25, 1942-1953. [CrossRef] [PubMed]

2. Agca, C.; Bidwell, C.A.; Donkin, S.S. Cloning of bovine pyruvate carboxylase and 5' untranslated region variants. Anim. Biotechnol. 2004, 15, 47-66. [CrossRef]

3. Wang, D.; Zou, L.; Jin, Q.; Hou, J.; Ge, G.; Yang, L. Human carboxylesterases: A comprehensive review. Acta Pharm. Sin. B 2018, 8, 699-712. [CrossRef] [PubMed]

4. Zhang, T.; Han, W.-J.; Liu, Z.-P. Gene cloning and characterization of a novel esterase from activated sludge metagenome. Microb. Cell Factories 2009, 8, 67. [CrossRef] [PubMed]

5. Taylor, P.; Radić, Z. The cholinesterases: From genes to proteins. Annu. Rev. Pharmacol. Toxicol. 1994, 34, 281-320. [CrossRef] 
6. Vogt, R.G.; Riddiford, L.M.; Prestwich, G.D. Kinetic properties of a sex pheromone-degrading enzyme: The sensillar esterase of Antheraea polyphemus. Proc. Natl. Acad. Sci. USA 1985, 82, 8827-8831. [CrossRef]

7. Fachinello, J.; Musacchi, S.; Zuccherelli, S.; Sansavini, S. Isoenzymatic variability in pear tissues for fingerprinting. Pesqui. Agropecuária Bras. 2000, 35, 1427-1432. [CrossRef]

8. Manganaris, A.G.; Alston, F.H. Genetics of esterase isoenzymes in Malus. Theor. Appl. Genet. 1992, 83, 467-475. [CrossRef]

9. Tanksley, S.D.; Rick, C.M. Genetics of esterases in species of Lycopersicon. Theor. Appl. Genet. 1980, 56, $209-219$. [CrossRef]

10. Akoh, C.C.; Lee, G.-C.; Liaw, Y.-C.; Huang, T.-H.; Shaw, J.-F. GDSL family of serine esterases/lipases. Prog. Lipid Res. 2004, 43, 534-552. [CrossRef]

11. Forouhar, F.; Yang, Y.; Kumar, D.; Chen, Y.; Fridman, E.; Park, S.W.; Chiang, Y.; Acton, T.B.; Montelione, G.T.; Pichersky, E.; et al. Structural and biochemical studies identify tobacco SABP2 as a methyl salicylate esterase and implicate it in plant innate immunity. Proc. Natl. Acad. Sci. USA 2005, 102, 1773-1778. [CrossRef] [PubMed]

12. Kim, Y.S.; Lee, H.H.; Ko, M.K.; Song, C.E.; Bae, C.Y.; Lee, Y.H.; Oh, B.J. Inhibition of fungal appressorium formation by pepper (Capsicum annuum) esterase. Mol. Plant. Microbe Interact. 2001, 14, 80-85. [CrossRef] [PubMed]

13. Marshall, S.D.G.; Putterill, J.J.; Plummer, K.M.; Newcomb, R.D. The carboxylesterase gene family from Arabidopsis thaliana. J. Mol. Evol. 2003, 57, 487-500. [PubMed]

14. Akashi, T.; Aoki, T.; Ayabe, S. Molecular and biochemical characterization of 2-hydroxyisoflavanone dehydratase. involvement of carboxylesterase-like proteins in leguminous isoflavone biosynthesis. Plant Physiol. 2005, 137, 882-891. [CrossRef]

15. Ueguchi-Tanaka, M.; Ashikari, M.; Nakajima, M.; Itoh, H.; Katoh, E.; Kobayashi, M.; Chow, T.; Hsing, Y.C.; Kitano, H.; Yamaguchi, I.; et al. Gibberellin insensitive dwarf1 encodes a soluble receptor for gibberellin. Nature 2005, 437, 693-698. [CrossRef]

16. Gershater, M.C.; Edwards, R. Regulating biological activity in plants with carboxylesterases. Plant Sci. 2007, 173, 579-588. [CrossRef]

17. Pontier, D.; Godiard, L.; Marco, Y.; Roby, D. hsr203J, a tobacco gene whose activation is rapid, highly localized and specific for incompatible plant/pathogen interactions. Plant J. Cell Mol. Biol. 1994, 5, 507-521. [CrossRef]

18. Hasslacher, M.; Schall, M.; Hayn, M.; Griengl, H.; Kohlwein, S.D.; Schwab, H. Molecular cloning of the full-length cDNA of (s)-hydroxynitrile lyase from Hevea brasiliensis. Functional expression in Escherichia coli and Saccharomyces cerevisiae and identification of an active site residue. J. Biol. Chem. 1996, 271, 5884-5891. [CrossRef]

19. Hughes, J.; Decarvalho, J.P.C.; Hughes, M.A. Purification, characterization, and cloning of $\alpha$-hydroxynitrile lyase from Cassava (Manihot esculenta Crantz). Arch. Biochem. Biophys. 1994, 311, 496-502. [CrossRef]

20. Yang, Y.; Xu, R.; Ma, C.; Vlot, A.C.; Klessig, D.F.; Pichersky, E. Inactive methyl indole-3-acetic acid ester can be hydrolyzed and activated by several esterases belonging to the AtMES esterase family of Arabidopsis. Plant Physiol. 2008, 147, 1034-1045. [CrossRef]

21. Carvalho, R.A.; Omoto, C.; Field, L.M.; Williamson, M.S.; Bass, C. Investigating the molecular mechanisms of organophosphate and pyrethroid resistance in the fall armyworm Spodoptera frugiperda. PLoS ONE 2013, 8, e62268. [CrossRef] [PubMed]

22. Gershater, M.C.; Cummins, I.; Edwards, R. Role of a carboxylesterase in herbicide bioactivation in Arabidopsis thaliana. J. Biol. Chem. 2007, 282, 21460-21466. [CrossRef] [PubMed]

23. Morel, J.B.; Dangl, J.L. The hypersensitive response and the induction of cell death in plants. Cell Death Differ. 1997, 4, 671-683. [CrossRef] [PubMed]

24. Bashir, Z.; Ahmad, A.; Shafique, S.; Anjum, T.; Shafique, S.; Akram, W. Hypersensitive response-A biophysical phenomenon of producers. Eur. J. Microbiol. Immunol. 2013, 3, 105-110. [CrossRef]

25. Dodds, P.; Thrall, P. Recognition events and host-pathogen co-evolution in gene-for-gene resistance to flax rust. Funct. Plant Biol. FPB 2009, 36, 395-408. [CrossRef]

26. Pontier, D.; Baudouin, E.; Czernic, P.; Tronchet, M.; Godiard, L.; Bezombes, I.; Deslandes, L.; Charpenteau, M.; Veronesi, C.; Sueur, J.; et al. Transcriptional regulation and function of hsr203j, an hypersensitivity-related gene of tobacco activated in response to Ralstonia solanacearum. In Bacterial Wilt Disease: Molecular and Ecological Aspects; Prior, P., Allen, C., Elphinstone, J., Eds.; Springer: Berlin/Heidelberg, Germany, 1998; pp. 203-208. 
27. Pontier, D.; Tronchet, M.; Rogowsky, P.; Lam, E.; Roby, D. Activation of hsr203, a plant gene expressed during incompatible plant-pathogen interactions, is correlated with programmed cell death. Mol. Plant. Microbe Interact. 1998, 11, 544-554. [CrossRef]

28. Cunnac, S.; Wilson, A.; Nuwer, J.; Kirik, A.; Baranage, G.; Mudgett, M.B. A conserved carboxylesterase is a suppressor of avrbst-elicited resistance in Arabidopsis. Plant Cell 2007, 19, 688-705. [CrossRef]

29. Cooper, B. Collateral gene expression changes induced by distinct plant viruses during the hypersensitive resistance reaction in Chenopodium amaranticolor. Plant J. Cell Mol. Biol. 2001, 26, 339-349. [CrossRef]

30. DeYoung, B.J.; Innes, R.W. Plant NBS-LRR proteins in pathogen sensing and host defense. Nat. Immunol. 2006, 7, 1243-1249. [CrossRef]

31. Gururani, M.A.; Venkatesh, J.; Upadhyaya, C.P.; Nookaraju, A.; Pandey, S.K.; Park, S.W. Plant disease resistance genes: Current status and future directions. Physiol. Mol. Plant Pathol. 2012, 78, 51-65. [CrossRef]

32. Deslandes, L.; Olivier, J.; Peeters, N.; Feng, D.X.; Khounlotham, M.; Boucher, C.; Somssich, I.; Genin, S.; Marco, Y. Physical interaction between RRS1-R, a protein conferring resistance to bacterial wilt, and PopP2, a type III effector targeted to the plant nucleus. Proc. Natl. Acad. Sci. USA 2003, 100, 8024-8029. [CrossRef] [PubMed]

33. Xiang, T.; Zong, N.; Zou, Y.; Wu, Y.; Zhang, J.; Xing, W.; Li, Y.; Tang, X.; Zhu, L.; Chai, J.; et al. Pseudomonas syringae effector AvrPto blocks innate immunity by targeting receptor kinases. Curr. Biol. 2008, 18, 74-80. [CrossRef] [PubMed]

34. Kroj, T.; Chanclud, E.; Michel-Romiti, C.; Grand, X.; Morel, J.-B. Integration of decoy domains derived from protein targets of pathogen effectors into plant immune receptors is widespread. New Phytol. 2016, 210, 618-626. [CrossRef]

35. Postel, S.; Kemmerling, B. Plant systems for recognition of pathogen-associated molecular patterns. Semin. Cell Dev. Biol. 2009, 20, 1025-1031. [CrossRef]

36. Padgett, H.S.; Beachy, R.N. Analysis of a tobacco mosaic virus strain capable of overcoming N gene-mediated resistance. Plant Cell 1993, 5, 577-586.

37. Abbink, T.E.M.; Tjernberg, P.A.; Bol, J.F.; Linthorst, H.J.M. Tobacco mosaic virus helicase domain induces necrosis in $\mathrm{n}$ gene-carrying tobacco in the absence of virus replication. Mol. Plant. Microbe Interact. 1998, 11, 1242-1246. [CrossRef]

38. Erickson, F.L.; Holzberg, S.; Calderon-Urrea, A.; Handley, V.; Axtell, M.; Corr, C.; Baker, B. The helicase domain of the TMV replicase proteins induces the N-mediated defence response in tobacco. Plant J. Cell Mol. Biol. 1999, 18, 67-75. [CrossRef]

39. Cao, C.-W.; Zhang, J.; Gao, X.-W.; Liang, P.; Guo, H.-L. Overexpression of carboxylesterase gene associated with organophosphorous insecticide resistance in cotton aphids, Aphis gossypii (Glover). Pestic. Biochem. Physiol. 2008, 90, 175-180. [CrossRef]

40. Gong, Y.-H.; Yu, X.-R.; Shang, Q.-L.; Shi, X.; Gao, X.-W. Oral delivery mediated rna interference of a carboxylesterase gene results in reduced resistance to organophosphorus insecticides in the cotton aphid, Aphis gossypii Glover. PLoS ONE 2014, 9, e102823. [CrossRef]

41. Ko, M.; Cho, J.H.; Seo, H.-H.; Lee, H.-H.; Kang, H.-Y.; Nguyen, T.S.; Soh, H.C.; Kim, Y.S.; Kim, J.-I. Constitutive expression of a fungus-inducible carboxylesterase improves disease resistance in transgenic pepper plants. Planta 2016, 244, 379-392. [CrossRef]

42. Bendahmane, A.; Kanyuka, K.; Baulcombe, D.C. The Rx gene from potato controls separate virus resistance and cell death responses. Plant Cell 1999, 11, 781-791. [CrossRef] [PubMed]

43. Kachroo, P.; Yoshioka, K.; Shah, J.; Dooner, H.K.; Klessig, D.F. Resistance to turnip crinkle virus in arabidopsis is regulated by two host genes and is salicylic acid dependent but NPR1, ethylene, and jasmonate independent. Plant Cell 2000, 12, 677-690. [CrossRef] [PubMed]

44. Gielen, J.; Ultzen, T.; Bontems, S.; Loots, W.; van Schepen, A.; Westerbroek, A.; de Haan, P.; van Grinsven, M. Coat protein-mediated protection to cucumber mosaic virus infections in cultivated tomato. Euphytica 1996, 88, 139-149. [CrossRef] 
45. Beachy, R.N. Coat-protein-mediated resistance to tobacco mosaic virus: Discovery mechanisms and exploitation. Philos. Trans. R. Soc. B Biol. Sci. 1999, 354, 659-664. [CrossRef]

46. Asurmendi, S.; Berg, R.H.; Koo, J.C.; Beachy, R.N. Coat protein regulates formation of replication complexes during tobacco mosaic virus infection. Proc. Natl. Acad. Sci. USA 2004, 101, 1415-1420. [CrossRef]

(C) 2020 by the authors. Licensee MDPI, Basel, Switzerland. This article is an open access article distributed under the terms and conditions of the Creative Commons Attribution (CC BY) license (http://creativecommons.org/licenses/by/4.0/). 